\title{
Living Actively for Good Health: Elders ${ }^{1}$
}

Jennifer Hillan and Anne Kendall ${ }^{2}$

If you think physical activity is limited to strenuous activities like exercise classes and sports, think again! Read on to learn why physical activity is important and how you can get started.

\section{What is Physical Activity and Why is it Important?}

Physical activity is any body movement that uses energy, including daily activities such as house or yard work and walking. Regular physical

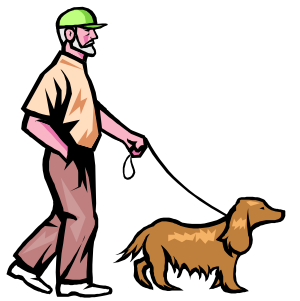
activity helps keep the heart, lungs, bones, muscles, and joints healthy. It also helps:

$\checkmark$ improve energy level and self-esteem

$\checkmark$ decrease stress and depression

$\checkmark$ manage weight

$\checkmark$ increase strength and flexibility

$\checkmark$ control arthritis pain

$\checkmark$ prevent or delay some diseases, such as heart disease and osteoporosis

$\checkmark$ improve balance and decrease the risk of falling

Being active can help you improve your quality of life and stay independent longer.

\section{How Much and What Types of Activity do I Need?}

Aim for at least 30 minutes of moderateintensity activity most days of the week. Moderate-intensity activity is not strenuous, but it should slightly increase your breathing and heart rate. Try climbing stairs, walking, or vacuuming.

Do some strength exercises 2 or 3 times a week. With stronger muscles, you'll be able to do more things on your own. You don't need fancy weights; use books or canned soup!

Include balance and flexibility (stretching) exercises at least twice a week. These will help prevent falls and keep your body limber.

Order the free exercise guide listed on

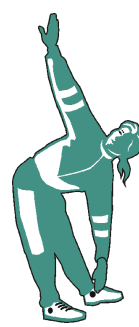
the next page for examples of strength, flexibility, and balance exercises.

1. This publication is FCS8753-Eng, one of a series of the Department of Family, Youth and Community Sciences, Florida Cooperative Extension Service, Institute of Food and Agricultural Sciences, University of Florida. Publication date: August 2002. Reviewed by Sergio Romero, MS, ATC, Department of Family, Youth and Community Sciences. Please visit the EDIS Web site at http://edis.ifas.ufl.edu

2. Jennifer Hillan, MSH, RD, LD/N, coordinator, Educational/Training Programs, Department of Family, Youth and Community Sciences; Anne Kendall, $\mathrm{PhD}, \mathrm{RD}, \mathrm{LD} / \mathrm{N}$, lecturer, Department of Food Science and Human Nutrition, Cooperative Extension Service, Institute of Food and Agricultural Sciences, University of Florida, Gainesville, 32611. 
If physical activity sounds overwhelming, don't despair! If you haven't been active, start slowly and increase your activity gradually. Remember, doing something is better than doing nothing!

\section{Beating the Barriers}

Not enough time. Remember the goal is to get at least 30 minutes of activity during day. It doesn't have to be all at once.

$\checkmark$ Work in the garden in the morning.

$\checkmark$ Mop your floor while watching TV.

$\checkmark$ Take a short walk after dinner.

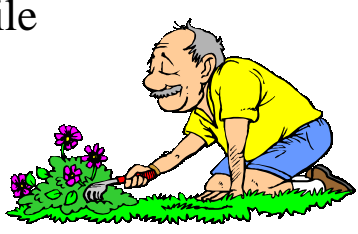

Too boring. Choose activities that you enjoy and invite a friend along. Vary your activities and routines-try a different walking path.

Not motivated. Set realistic short and longterm goals. Reward yourself when you reach them! Keep an activity log so you can look back and see how far you've come. Find an exercise partner!

Not enough energy. Physical activity actually increases your energy level. Be active for 5 minutes and if you're tired after that time, stop. But chances are you'll feel like continuing!

\section{Tips for Keeping it Safe}

Get a check-up. Most elders can safely be more physically active, no matter what age or condition. However, first talk with your health care provider if:

- you have diabetes, heart disease, or another chronic health condition

- you are at high risk for heart disease

- you plan to start doing vigorous activity (activity that makes you breathe and sweat hard)

Drink water before, during, and after activity.

Warm up and cool down. Some light activity and stretching before and after your moderateintensity activity reduces your risk of injury.

Be cautious. Tell someone where you are going, and wear reflective clothing or shoes if you are outside at night.

\section{How Much is Too Much?}

Your body will tell you if you're doing too much. Pay attention to early warning pains and don't push yourself so much that your activity is no longer enjoyable. Seek medical advice if you become dizzy or have an injury, severe muscle soreness, or chest pain.

For a free exercise guide from the National Institute on Aging, call 1-800-222-2225 (tollfree) and ask for publication number NIH 99-4258.

It's easy to get started and make regular physical activity a lifelong habit!

$\checkmark$ Talk to your health care provider if needed.

$\checkmark$ Choose an activity you enjoy.

$\checkmark$ Start slowly and increase your activity gradually. 